\title{
Protected Culture for Vegetable and Small Fruit Crops: Southern Highbush Blueberry Cultivars under High Tunnels ${ }^{1}$
}

\author{
Bielinski M. Santos and Teresa P. Salame-Donoso²
}

\section{Blueberry production in Florida}

In 2010 in the United States, blueberry (Vaccinium spp.) was produced on more than 68,000 acres. In 2013 Commercial blueberries were reported being harvested from approximately 4,800 acres in Florida, resulting in a crop value of nearly $\$ 70$ million. Southern highbush blueberry farms are located throughout Florida in areas receiving between approximately 200 and 400 hours of chill (hours of temperatures between $32^{\circ} \mathrm{F}$ and $45^{\circ} \mathrm{F}$ ) during the dormant period.

Blueberries are transplanted in open fields into ground cloth-covered or bare-soil hills and irrigated with overhead sprinklers, microsprinklers, or drip lines. The soils in the majority of southern highbush blueberry growing areas are sandy with rapid drainage and slightly alkaline $\mathrm{pH}$. Planting beds are typically formed with pine bark or with a mix of pine bark rototilled into the sandy soil. These practices lower soil $\mathrm{pH}$ from the pine bark acidity $(\mathrm{pH}<$ 6 ) and promote rapid drainage during the rainy summer months. Planting densities vary depending on cultivar, but the most common are between 1,600 and 2,800 plants/ acre. Southern highbush blueberry flowering occurs from January to March, and most of the cultivars in Florida have chilling requirements between 200 and 400 hours. Fruit are harvested from early April to mid-May. The highest market prices occur before May 15, dropping from about $\$ 7.00 / \mathrm{lb}$ in March to around \$3.00/lb in May. Practices that improve earliness may allow for higher market prices.

Overhead irrigation ( 4 to $5 \mathrm{gal} / \mathrm{min}$ per sprinkler head) is the preferred freeze protection method. To obtain adequate freeze protection with sprinklers, the correct amount of water must be applied (precipitation rate of 0.15 to 0.3 acreinch/h per acre; 1 acre-inch $=27,154$ gal). The principle associated with this practice is called "heat of fusion," which is the heat released by water during the freezing process, in which $1 \mathrm{~g}$ of water releases 80 calories of heat as it forms ice. The primary disadvantage of this freeze protection method is that during prolonged freezing periods, it could quickly deplete underground water sources (e.g., aquifers), which might be shared with nearby urban settlements. A single night of freeze protection (8 to 12 hours of irrigation) with high-volume sprinklers might use between 2 and 3 acre-inch/acre of water, which could translate into very large water volumes to protect the crop. Water-saving technologies can reduce pressure on underground water sources, nutrient leaching potential, and electricity or fossil fuel costs for powering irrigation system pumps for growers.

High tunnels have been proposed as an alternative for freeze protection and to increase fruit earliness of southern highbush blueberry. High tunnels are generally unheated,

1. This document is HS1226, one of a series of the Horticultural Sciences Department, UF/IFAS Extension. Original publication date July 2013. Visit the EDIS website at http://edis.ifas.ufl.edu.

2. Bielinski M. Santos, associate professor, and Teresa P. Salame-Donoso, research assistant, Horticultural Sciences Department, Gulf Coast Research and Education Center, UF/IFAS Extension, Wimauma, FL 33598. 
plastic-covered structures with passive ventilation. Potential benefits of high tunnels for vegetable and small fruit production include freeze protection, high early yields, protection against some diseases and rain, plus efficient fertilizer and water use. High tunnels may increase air and soil temperatures in areas of cold weather. However, there is no information about the effect of this type of structure on southern highbush blueberry fruit earliness under subtropical Florida conditions.

\section{Comparison of blueberry cultivars under high tunnels}

A 2-year study was conducted over two production seasons in a commercial southern highbush blueberry farm in North Central Florida to compare early fruit weight in high tunnels to that of open fields. Planting beds ( $1.5 \mathrm{ft}$ tall by 4 $\mathrm{ft}$ wide) were formed by placing fine pine bark chips on top of the native sandy soil and covering them with 50 mil of black groundcover. Irrigation was provided by a single drip line $(0.30 \mathrm{gal} / 100 \mathrm{ft}$ of bed per min) with emitters separated at $2 \mathrm{ft}$. Three-year-old 'Snow Chaser' and 'Springhigh' southern highbush blueberry plants were planted in single rows with $10 \mathrm{ft}$ between rows and $2.5 \mathrm{ft}$ between plants, resulting in a planting density of 1,720 plants/acre.

Passively ventilated high tunnels ( $18 \mathrm{ft}$ high, $25 \mathrm{ft}$ wide, and $600 \mathrm{ft}$ long) made of galvanized steel were used and built over established plants. From May to August of each year, the plastic roof ( 6 mil thick, 35\% light reduction polyethylene) and sides were completely removed. For freeze protection, the open field was equipped with sprinklers (4.5 $\mathrm{gal} / \mathrm{min}$ ) that delivered approximately $120 \mathrm{gal} / \mathrm{min}$ per acre of water, whereas minisprinklers $(0.5 \mathrm{gal} / \mathrm{min})$ inside the high tunnels applied approximately $60 \mathrm{gal} / \mathrm{min}$ per acre. The irrigation system for freeze protection was turned on at $34^{\circ} \mathrm{F}$, and it was controlled independently within each production system. This temperature was chosen because Florida growers use it as a threshold from which to start sprinkler irrigation. During cold weather events, the high tunnel ends and sides were totally closed between 12 and 24 hours before the forecast freeze, and they were not ventilated until temperatures reached approximately $50^{\circ} \mathrm{F}$ inside the structures.

The study used four combinations of two southern highbush blueberry cultivars ('Snow Chaser' and 'Springhigh') and two production systems (open field and high tunnel). Plots consisted of 10 plants each, and early fruit weight was recorded from weekly harvests starting on February 15 and running until April 15 of each season, totaling nine weekly harvests per season. The same plants were harvested each season. Temperature data loggers were installed at $3 \mathrm{ft}$ above ground level in each high tunnel plot to record daily maximum and minimum air temperatures between September and April of each season. The number of days when the minimum temperature reached $34^{\circ} \mathrm{F}$ or less was also recorded.

In $2009-10$, there were 22 days at or below $34^{\circ} \mathrm{F}$ in the open-field plots and only 5 days of such temperatures inside the high tunnels from January to March. During the following season, air temperatures in the plots located inside the high tunnels dropped at or below $34^{\circ} \mathrm{F}$ only twice. The open-field plots received 15 freezing or near-freezing events during this same time frame. The minimum air temperature in open-field plots reached approximately $19^{\circ} \mathrm{F}$ and $21^{\circ} \mathrm{F}$ in the 2009-10 and 2010-11 seasons, respectively. In contrast, the minimum air temperatures inside the high tunnels were about $32^{\circ} \mathrm{F}$ and $33^{\circ} \mathrm{F}$, respectively, during the same seasons. This indicates that using high tunnels was an effective means to avoid freezing or near-freezing air temperatures because they prevented freezing 30 times out of 37 days of such temperatures during both years, with the remaining three freeze or near-freeze events occurring around $32^{\circ} \mathrm{F}$. Maximum air temperature did not differ inside and outside the structures between September and April of each year.

During the 2009-10 season, there were no early fruit weight differences among the treatments up to March 15 (Figure 1). However, both cultivars produced an average of approximately 4.5 ton/acre of fruit by March 30 when planted inside the high tunnels, but nothing in the open-field plots during this time frame. At this point, there was no cumulative early fruit weight difference between the two cultivars. During the final harvest, the cumulative early fruit weight was the highest in plots planted with 'Snow Chaser' inside the high tunnels (about 10 ton/acre), followed by those planted with 'Springhigh' under the structures (approximately 7 ton/acre). The combined production of these two cultivars in the open fields did not reach 1 ton/acre until April 15, 2010.

On February 28, 2011, cumulative early fruit production of 'Snow Chaser' was approximately 2.5 ton/acre inside the high tunnels, whereas there were no differences among the other three combinations, which revealed the earliness of this cultivar under protected culture (Figure 1). There was no open-field production at this point in time. On March 15, the cumulative early yield reached 4.5 ton/acre for 'Snow Chaser' growing inside the high tunnels, while there were no measurable early fruit differences across the other treatments, regardless of the production system. 

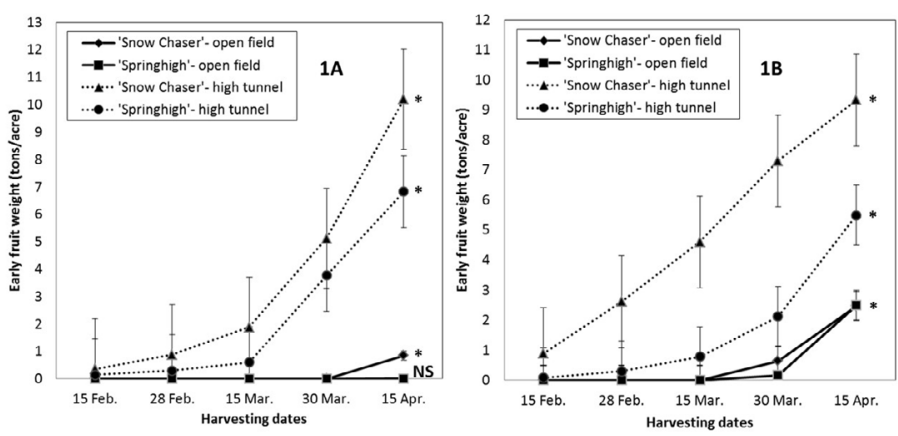

Figure 1. 1A and 1B. Effects of production systems on the cumulative early southern highbush blueberry fruit weight at Waldo, Florida, in 2009-10 (Fig. 1A) and 2010-11 (Fig. 1B).

Two weeks later, the cumulative early fruit weight of 'Springhigh' inside the high tunnels was around 2 ton/acre, which was significantly higher than the yields obtained with this same cultivar in the open fields up to harvest time ( 0.15 ton/acre). Still, 'Snow Chaser' production in the high tunnels surpassed 7 ton/acre by March 30. By the final harvest, there were no differences in the cumulative early fruit weight of both cultivars when planted in the open fields (2.2 ton/acre). The cumulative fruit yield of 'Springhigh' growing inside the high tunnels was twice as much as that obtained with the same cultivar in the open fields. Moreover, 'Snow Chaser' early production under the structures was more than four times higher than early fruit production in the open fields, which was likely due to the effect of high tunnels on flower protection and fruit setting and maturation.

These results demonstrate that high tunnels for southern highbush blueberry production in Florida has profound effects on fruit earliness and water use for frost protection. Fruit earliness increased by almost four weeks, especially with 'Snow Chaser'. From an environmental standpoint, high tunnels reduced water need for freeze protection. For instance, the total volume used in the open fields during the freezing or near-freezing days (37 events) was approximately 2.5 acre-inch/acre per 8 hours of freeze protection (92.5 acre-inch/acre during both seasons), whereas water was applied only during seven nights inside the structures, with a smaller amount of water. These water savings demonstrate that this method is effective for protecting young buds, flowers, and fruit against rain and ice injury, which in turn reduces the proportion of nonmarketable fruit. On the physiological side, it is also likely the high tunnels and the higher temperatures inside them allowed the plants to continue setting fruit at times when freezing temperatures were present in the open fields, which may allow growers to take advantage of high market prices during this part of the season (Figure 2). At current market prices between $\$ 18,000$ and $\$ 25,000 /$ acre for high tunnels (not including labor to set up the structures), it is necessary to conduct an in-depth economic analysis to determine the actual return over time.

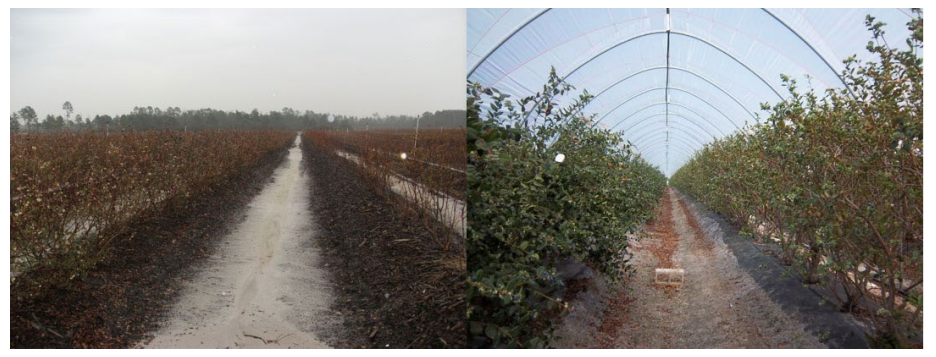

Figure 2. Blueberry plants growing in open fields (left) and inside high tunnels (right) in early January in north-central Florida.

Credits: B.M. Santos

In depth studies need to be conducted because cultivar performance in high tunnels may be somewhat different from open fields. Challenges include pollination (honey bees do not survive well inside high tunnels, thus bumblebees should be used), proper ventilation in summer months, and non-uniform fruit coloration in some cultivars. Generally, total yields are much higher in high tunnels, but only a fraction of the total production ripens during the ideal window.

\section{Acknowledgements}

The authors wish to thank the Specialty Crop Block Grant Program, Florida Department of Agriculture and Consumer Services, for financial support. 